\title{
T4 Endonuclease V
}

National Cancer Institute

\section{Source}

National Cancer Institute. T4 Endonuclease V. NCI Thesaurus. Code C17538.

A DNA repair enzyme from bacteriophage T4. It catalyzes the first reaction step of the excision repair pathway to remove pyrimidine-dimers produced within duplex DNA by UV irradiation. It has been incorporated into a topical lotion for treatment of xeroderma pigentosum. 